\title{
BMJ Open The effects of health behaviours and beliefs based on message framing among patients with chronic diseases: a systematic review
}

\author{
Ruitong Gao, ${ }^{1}$ Hui Guo, ${ }^{2}$ Fei Li, ${ }^{3}$ Yandi Liu, ${ }^{3}$ Meidi Shen, ${ }^{1}$ Linqi Xu, ${ }^{1}$ Tianzhuo Yu, ${ }^{1}$ \\ Feng Li (D) ${ }^{1}$
}

To cite: Gao R, Guo H, Li F, et al. The effects of health behaviours and beliefs based on message framing among patients with chronic diseases: a systematic review. BMJ Open 2022;12:e055329. doi:10.1136/ bmjopen-2021-055329

- Prepublication history and additional supplemental material for this paper are available online. To view these files, please visit the journal online (http://dx.doi.org/10.1136/ bmjopen-2021-055329).

Received 10 July 2021 Accepted 21 December 2021

D) Check for updates

(c) Author(s) (or their employer(s)) 2022. Re-use permitted under CC BY-NC. No commercial re-use. See rights and permissions. Published by BMJ.

${ }^{1}$ School of Nursing, Jilin University, Changchun, Jilin, China

${ }^{2}$ Department of Endocrinology and Metabolism, Eastern Division of the First Bethune Hospital of Jilin University, Changchun, China

${ }^{3}$ Department of Endocrinology and Metabolism, First Bethune Hospital of Jilin University, Changchun, China

Correspondence to

Professor Feng Li; fl@jlu.edu.cn

\section{ABSTRACT}

Objective The effectiveness of integrating message framing into educational interventions to promote the health behaviour of patients with chronic diseases is still being debated in nursing research. The objective of this study was to assess the impact of educational interventions based on gain and loss frames on the health behaviours and beliefs of patients with chronic diseases and to identify the frame that achieves better outcomes.

Design The systematic review was based on PRISMA guidelines for comprehensively searching, appraising and synthesising research evidence.

Data sources We searched the PubMed, Web of Science, PsycINF0 and CINAHL databases for reports published from database inception until 26 March 2021.

Eligibility criteria Intervention studies, published in English, with adult patients with chronic disease conditions, and with intervention contents involved in the implementation of message framing, were considered. The outcomes were health behaviours or beliefs, such as knowledge, self-efficacy, intention or attitudes.

Data extraction and synthesis Data extraction and entry were performed using a predesigned data extraction form and assessed independently by two reviewers using the Cochrane Collaboration Risk of Bias I.

Results A total of 11 intervention studies were included. We found that educational intervention based on both gain and loss frames could enhance the positive effects of communication, and promote healthy behaviours and beliefs in patients with chronic disease. Many of the studies we included here showed the advantage of loss framing messages. Due to the limited number of articles included and without quantitative analysis, this result should be interpreted cautiously.

Conclusions Integrating message framing into health education might be a promising strategy to motivate patients with chronic disease to improve their health behaviours and beliefs. More extensive and well-designed trials are needed to support the conclusions and discuss the effective framing, moderators and mediators of framing.

PROSPERO registration number CRD42021250931.

\section{Strengths and limitations of this study}

- This systematic review has extracted evidence from interventional studies, which provided a theoretical and evidence base for practice.

- A limited number of randomised clinical trials were included, limiting the quality of the evidence.

- Heterogeneity of different patient samples and health messages and the diversity of outcome measurements did not permit quantitative analysis.

\section{INTRODUCTION}

Chronic diseases have become the leading cause of morbidity and mortality worldwide, accounting for 41 million deaths, more than $70 \%$ of all deaths and $80 \%$ of total disabilities. ${ }^{12}$ An ageing population, lifestyle factors influencing diseases such as high-fat diets and low levels of physical activity indicate that this trend will continue to increase. ${ }^{3}$ More than 300 million people in China have been diagnosed with chronic diseases since $2018{ }^{4}$ The rising burden of various diseases has increased medical expenses; for example, diabetes, a common chronic disease: according to the International Diabetes Federation, diabetes-related direct medical expenditures amounted to approximately $\$ 25$ billion in China in 2017. ${ }^{5}$ Hence, the treatment and care of chronic diseases pose a significant impact on individuals, their families and societies, as well as a huge demand to healthcare systems. ${ }^{67}$

Providing health-related information and support to patients can encourage them to promote change and maintain their health behaviour, and improve their psychological and physiological outcomes, ${ }^{8}$ which effectively prevent and reduce complications associated with chronic diseases, risk of death and disease burden. ${ }^{9}$ Nurses play a critical role in educating patients about how to improve 
their health. When it comes to health information, nurses are just as reliable as doctors, and patients prefer to get it from nurses because they are more accessible than doctors. $^{81011}$ The number of people developing longterm conditions that in need of nursing care is increasing rapidly. ${ }^{12}$ The number of healthcare professionals, especially registered nurses, is far from meeting the current and future demands. ${ }^{12}{ }^{13}$ Thus, we need to explore a more effective way to deliver messages to patients to maximise the effectiveness of health management education.

The effectiveness of educational messages in promoting behaviour change may depend on how the message is presented rather than the meaning of the content itself. Message framing is a message tailoring method that can influence an individual's behavioural decision by adjusting the presentation of a message without changing the meaning of the content, thereby promoting a particular behaviour. ${ }^{14}$ The most common method is to develop a message based on the gain (positive) or loss (negative) frame. The benefits of adopting the target behaviour are typically emphasised in gain-framing messages, whereas the costs of not adopting the target behaviour are stressed in loss-framing information. ${ }^{14}$ In their reviews O'Keefe and Jensen found that positive frames were slightly better for disease prevention. However, when they classified disease prevention behaviours, only a slight advantage of positive framing was seen in dental hygiene behaviour, while there was no difference between the two frames for other disease prevention behaviours such as diet/nutrition behaviours, or exercise behaviours. ${ }^{15} 16$

Reviewing the past literature, several studies on health-related behaviours such as smoking, ${ }^{17}$ physical activity, ${ }^{18}$ dental hygiene, ${ }^{19}$ have emerged in messageframing research. Notably, many studies are examined in messaging framing effect on health-related behaviours in the general population rather than representative samples of people suffering from chronic diseases or high risk groups, such as diabetes and cardiovascular diseases. $^{20-22}$ At the same time, the effects of message framing on chronic disease education are inconsistent. For example, Grady et al found that a gain-framed foot care message was more effective in changing foot care behaviour in patients with diabetes. ${ }^{23}$ In contrast, Lee and Gu's study showed that loss-framed foot care messaging was more effective in activating attitudes and intentions to conduct foot care in patients with diabetes. ${ }^{24}$

There are many opportunities in nursing to provide patient health information in various settings, ranging from the distribution of written materials to teaching chronic disease self-management skills. ${ }^{12}$ Meanwhile, patients feel more open and free to communicate with nurses. ${ }^{11}$ Thus, nurses have significant opportunities to use message framing to provide health information. The primary purpose of this study was to review the impact of message framing educational interventions on the health behaviours and beliefs of patients with chronic disease, and to inform the design of future health information interventions.

\section{METHODS}

\section{Search strategy}

This systematic review was carried out based on PRISMA (Preferred Reporting Items for Systematic Reviews and Meta-Analyses) guidelines ${ }^{25}$ and recommendations of the Cochrane Collaboration. ${ }^{26}$ There was no need for ethical approval because the literature analysed in this study was from previously published studies. The PROSPERO (International Prospective Register of Systematic Reviews) registration number is CRD42021250931.

We searched for studies published in PubMed, Web of Science, PsycINFO and CINAHL (Cumulated Index to Nursing and Allied Health Literature), from their inception to 26 March 2021. Terms related to message framing and chronic diseases used in this article were retrieved, including message framing, information framing, gainframed, loss-framed, gain fram*, loss fram*, positive fram*, negative fram*, framing effect*, noncommunicable diseases, comorbidity, multimorbidity, chronic disease, chronic illness, chronic condition, long term condition, long term illness. The search strategies of each database are available in the online supplemental file 1. The reference lists of included and relevant publications were manually screened for additional articles.

\section{Study selection}

The inclusion criteria included adult patients aged 18 years or older with chronic diseases (diseases that persist and require care over time, such as cardiovascular conditions, diabetes and cancer), ${ }^{27} 28$ intervention contents involved in the application of message framing, including involving a comparison of a message-framing intervention with either a control intervention or other message frames, and intervention studies (randomised controlled trials (RCTs) or quasi-experimental studies) published as peer-reviewed full-text articles in the English language. Messages could be delivered in paper or electronic form, and there were no restrictions on who had delivered the intervention. These studies measured health behaviours or beliefs such as knowledge, self-efficacy, intention or attitude. Exclusion criteria included articles from patients with severe mental disorders or cognitive impairment.

The retrieval results were imported into Endnote $\mathrm{X}$ V.20 for literature management. Following the removal of duplicates, two independent researchers (RG, YL) screened the title, abstract and full text based on preestablished inclusion and exclusion criteria. If they found any disagreement, it was resolved by a third independent researcher (HG).

\section{Data extraction and analysis}

Data extraction and entry were performed using a predesigned data extraction form, including first author, year of publication, country, sample size, gender, age, key contents of intervention, outcome measures and findings. Two independent researchers completed data extraction (RG, LX), and if there was any disagreement 
or uncertainty, it was arbitrated and resolved by a third independent researcher (FL).

Although our initial goal was to complete a systematic review and meta-analysis, quantitative analysis could not be carried out due to the large statistical and clinical heterogeneity of the literature.

\section{Quality assessment}

Two independent researchers (RG, MS) completed quality assessment of the included articles using Cochrane Collaboration Risk of Bias I. ${ }^{29}$ If they found any uncertainty or difference in opinion, it was resolved by a third independent researcher (TY). For quasi-experimental studies without randomisation, the item of random sequence generation of selection bias was automatically identified as high risk. ${ }^{30} 31$

\section{Patient and public involvement}

Neither patients nor the public were involved in this research.

\section{RESULT}

\section{Literature search}

Total 2253 articles were systematically retrieved, after removing duplicate literature and screening the titles and abstracts, with 42 articles were read the full text. A total of 11 studies was included: ${ }^{23}{ }^{32-41} 10$ RCTs and 1 quasiexperimental study $^{33}$ based on previously established inclusion and exclusion criteria. Figure 1 illustrates the PRISMA flow chart of the literature screening process. ${ }^{25}$

\section{Characteristics of the included studies}

The included studies were published between 2004 and 2020 and came from Korea, the Philippines, the UK, China, the USA and Canada. The number of participants ranged from 49 to 1108 , for a total of 2216 , with the mean age ranging from 40 years to 71 years and the proportion of males was $43.7 \%$.

Diabetes, cardiovascular diseases and cancer were the most common chronic diseases addressed in the included literature. ${ }^{23} 3233353641$ Seven studies were set up in two groups, with one receiving educational intervention based on gain frame, and the other group receiving educational intervention based on loss frame. ${ }^{23} 3234-363940$ Only four studies were set up in three groups: a gain-framed group, a loss-frame group and a standard control group for providing usual care, with no message framing. ${ }^{33373841}$ The gain-framing condition highlighted the positive outcomes of completing or adhering to healthy behaviour, whereas the loss-framing condition emphasised the undesirable consequences of failing to comply or adhere to healthy behaviour, which corresponded with the positive-framing outcomes. Messages were delivered via video, pamphlets and online. Nine studies conducted the intervention only once $\mathrm{e}^{23} 32-3537-40$ and two studies sent pamphlets to patients to take home for further reading. ${ }^{3641}$ Online supplemental file 2 presents specific information about the included studies.

\section{Quality assessment of the included studies}

Regarding selection bias, two RCTs described adequate random sequence generation ${ }^{32} 37$ and other eight RCTs reported randomisation but did not report a specific

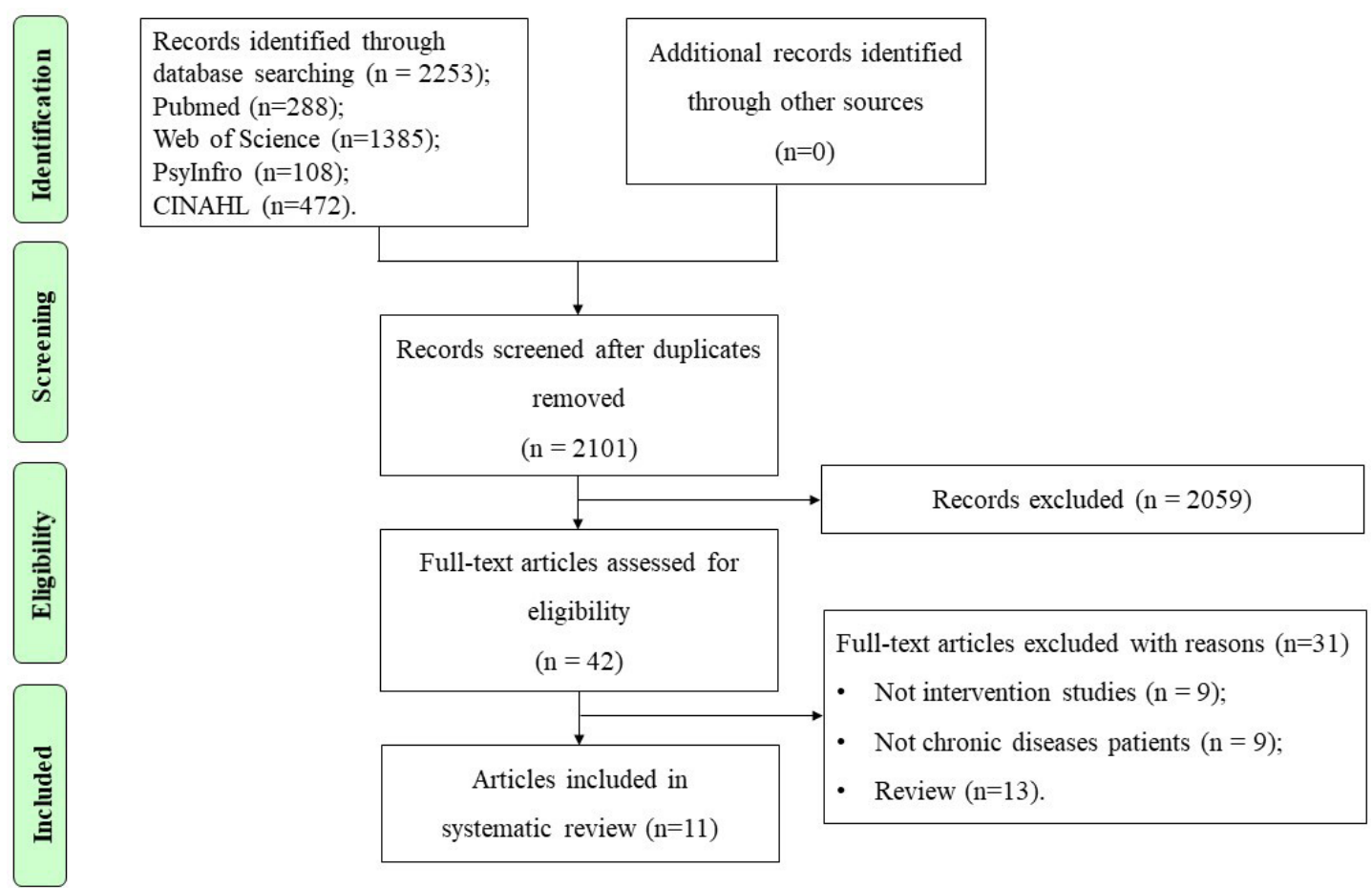

Figure 1 PRISMA flow chart. ${ }^{25}$ 


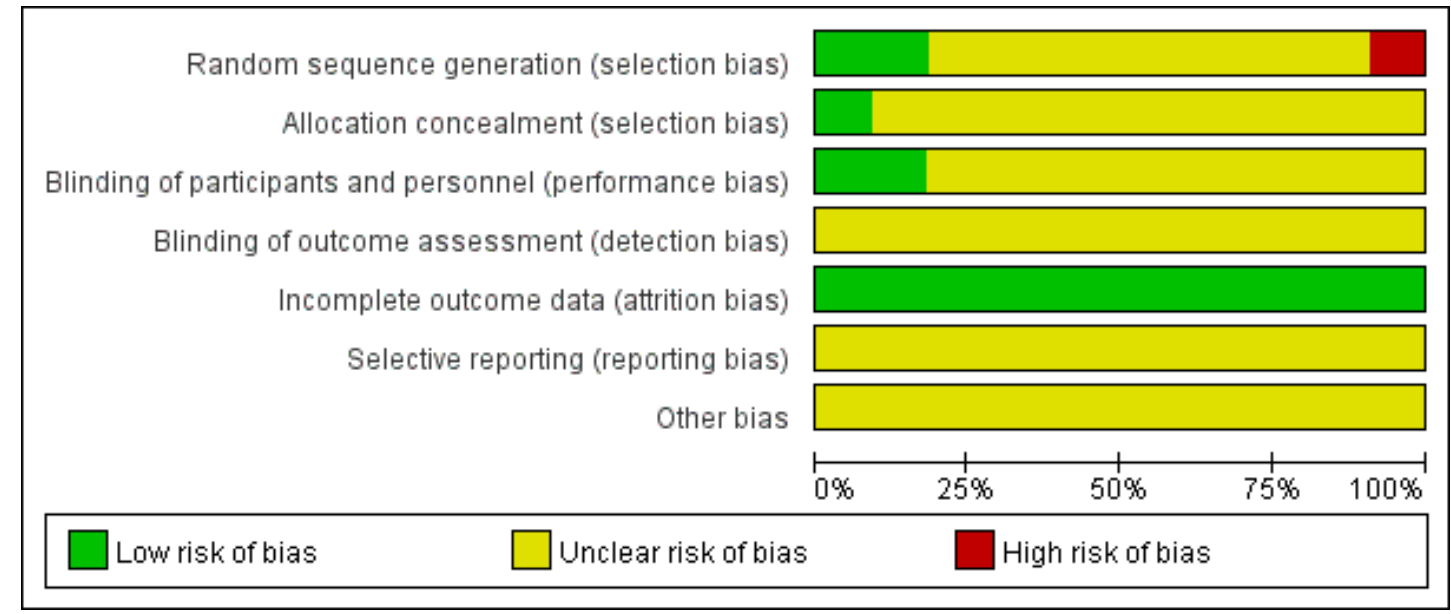

Figure 2 Risk of bias assessment.

method. ${ }^{2334-36 ~ 38-41}$ In one quasi-experimental study, nonrandomised sampling was used; participants were just assigned to different groups on separate visit days, identified as high risk. ${ }^{33}$ Only one study reported adequate allocation concealment, ${ }^{32}$ and the other 10 were rated as having an unclear risk of bias due to insufficient information. ${ }^{23} 33-41$ Only two studies showed a low risk of performance bias. ${ }^{33} 39$ The risk of detection bias was rated as unclear risk as none of the 11 articles indicated whether the blind method was applied to the outcome assessment. ${ }^{23} 32-41$ Regarding attrition bias, 11 studies were rated as low risk of bias. ${ }^{232-41}$ The reports and other sources of bias of the 11 studies were rated as having an unclear risk of bias due to insufficient information. ${ }^{23} 32-41$ Figures 2 and 3 summarise the quality assessment of the included studies.

\section{Main effects of framing}

Several studies have reported effects on numerous outcomes. Six studies assessed outcomes immediately after the intervention, ${ }^{32-34} 373840$ and five studies measured actual behaviour from 4 weeks to 12 months of follow-up. ${ }^{23} 35363941$ The content of message intervention primarily focused on healthy behaviours such as physical activity, medical adherence and self-management for patients with chronic disease. However, the outcomes measured in the 11 studies were too diverse to analyse quantitatively. Online supplemental file 3 presents a summary of findings from the studies included in this review.

Several studies reported significant main or interactive effects of framing. Among the included studies, five studies mainly explored the influence of educational interventions based on message framing on self-management behaviour and related cognitive variables of patients with chronic disease. $.^{23} 32-3440$ Three of the five studies showed the advantage of loss-framing messages. ${ }^{32} 3340$ Two studies found that loss-framed messages were superior to gainframed messages for improving the scores of intention, attitude and knowledge of self-management behaviour in patients with diabetes. However, the increase in intention and knowledge scores did not meet the criteria for statistical difference. ${ }^{32} 33$ One study found that loss-framed messages contributed more knowledge gain than gainframed messages to patients with chronic pain. ${ }^{40}$ On the other hand, one study found that a gain-framed message was slightly superior to a loss-framed message in sustaining long-term foot care behaviour change. ${ }^{23}$ Another study of patients with psoriasis found that when messages focused on long-term health risk, loss-framed messages were more persuasive to reducing alcohol intake intention, while in messages that focused on short-term health risk, gainframed messages were more persuasive than loss-framed messages. ${ }^{34}$

Four studies mainly explored the influence of educational interventions based on message framing on physical activity and related cognitive variables in patients with chronic disease. ${ }^{35-3741}$ Three of the four studies showed the advantage of loss-framed messages. ${ }^{35-37}$ One study found that loss-framed messages contributed more physical activity gain than gain-framed messages in patients with diabetes. ${ }^{35}$ Furthermore, one study found that in patients with spinal cord injury, the loss-framed messages group increased their physical activity intention than the gain-framed messages group and the usual care group, while there was no significant difference between the physical activity intention in the gain-frame group and the usual care group. ${ }^{37}$ One study reported that both gain-framed and loss-framed messages resulted in more physical activity than at baseline, and increased more in the loss-framed group, but the difference between the two groups did not reach statistical significance; neither gain-framing nor loss-framing elicited higher physical activity intention or attitude. ${ }^{36}$ In contrast, one study found that a gain-framed message was slightly superior to a loss-framed message in improving exercise adherence among patients with cardiovascular disease. ${ }^{41}$

Two studies primarily explored the influence of educational interventions based on message framing on adherence to medicine and treatment therapy and related cognitive variables in patients with chronic disease. ${ }^{38} 39$ 


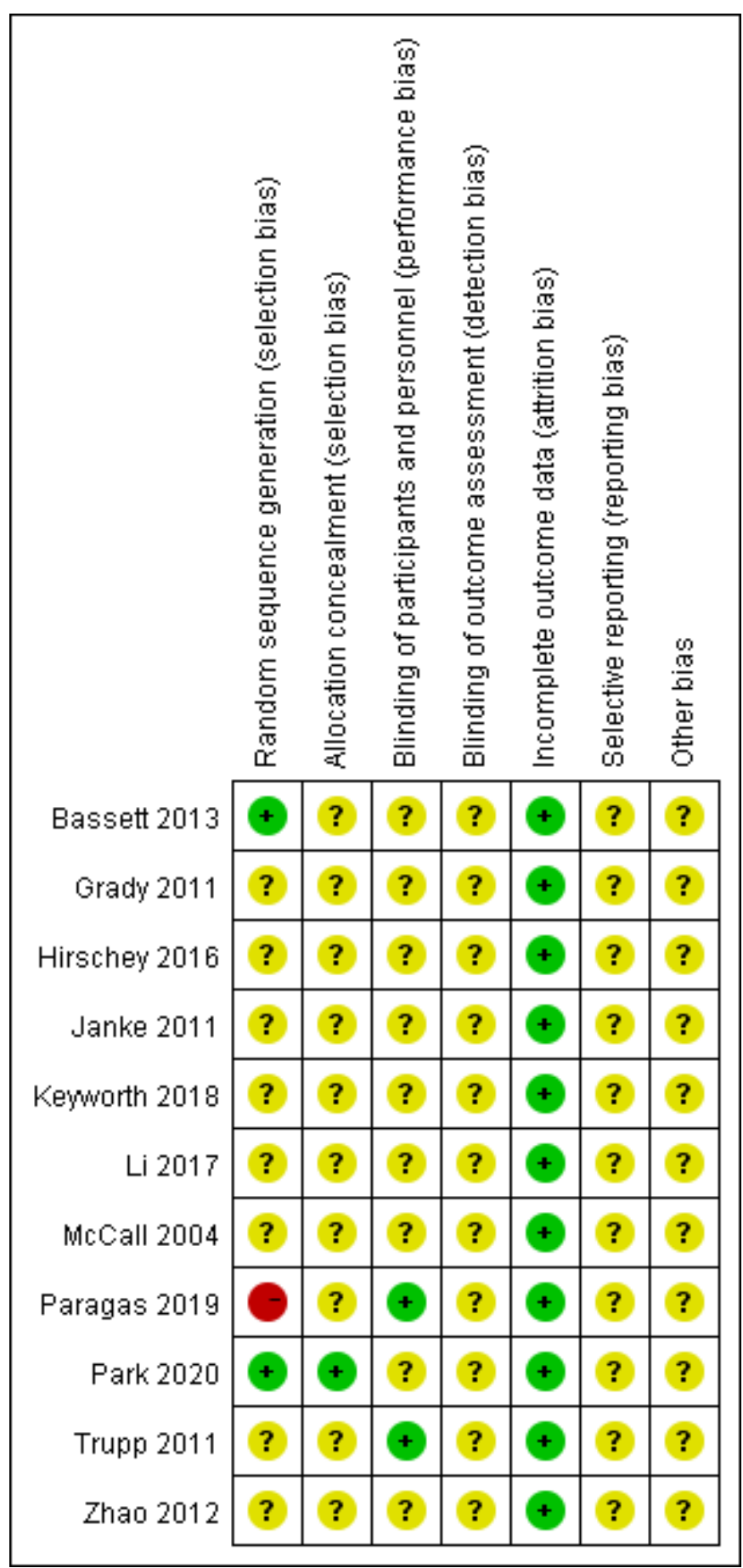

Figure 3 Risk of bias summary.

One study reported that loss-framed messages increased adherence to treatment therapy and self-efficacy more than gain-framed messages in patients with cardiovascular disease. ${ }^{39}$ Another study found that when compared with the usual care group, both gain-framed and loss-framed messages lead to higher medicine adherence intention and attitude, but without a difference between the two conditions. $^{38}$

\section{Moderator and mediator variables of framing effects}

Several studies focused on moderators and mediators of framing effects. In particular, Park et al reported that message framing had a significant indirect impact on intentions for diabetes self-care behaviour, mediated through attitudes and perceived control, but no significant differences between message framing groups. ${ }^{32}$ Grady et al performed regression analyses after the intervention. They found that changes in knowledge predicted changes in attitudes and that both framing and attitudes were predictors of long-term diabetes self-managemnt behaviour. ${ }^{23}$ Nevertheless, McCall's study observed no mediating effects between health belief model constructs and messages. ${ }^{41}$

Zhao et al investigated the interaction between frames and individual time perspective considering future consequences (CFC). They found a significant interaction between the two, which showed that among high-CFC patients, both gain-framed and loss-framed messages heightened medicine adherence intention and attitude towards no-message control. The message exposure did not affect the two outcomes in low-CFC and medium-CFC participants. ${ }^{38}$

\section{DISCUSSION}

Patients with chronic diseases need to maintain long-term health behaviours to avoid complications and improve their quality of life. It is necessary to explore the most effective method of conveying health educational information to patients to minimise the nurses' workload and improve patients' health behaviours. Message framing, as an effective message tailoring strategy, provides a new perspective for achieving this goal by increasing persuasiveness for promotion of healthy behaviours. Hence, we summarised the research on the influence of educational interventions based on message framing on health behaviour and related cognitive variables in patients with long-term illnesses. This research found that most studies showed educational message intervention based on the gain and loss frame could effectively improve health behaviours and cognitive variables such as health behaviour knowledge, intention, attitude and self-efficacy of patients with chronic diseases. Previous studies have suggested that gain framing is more effective for preventive behaviour, but is not concluded in this study. Many of the studies we included in this review showed the advantage of loss-framing messages, but due to the limited number of included articles and lack of quantitative analysis, this result should be interpreted with caution.

The persuasion of gain-framing and loss-framing appeal seems to be more complicated than previously thought. Many patients with chronic disease may have low health awareness and health literacy. ${ }^{42}{ }^{43}$ The loss framing might be more efficacious if people do not intend to take action in the foreseeable future and are unaware of the issues related to their behaviour. ${ }^{44}$ Besides, individuals weigh the benefits of engaging in healthy behaviours (such as reducing symptoms and improving mood) against the potential costs (such as the time and effort spent learning a new skill) ${ }^{40}$ Individuals suffering from chronic diseases, 
who typically have a long history of illness, may have had a learning history and outcome expectation (eg, perceived importance) that may have resulted in an avoidance tendency towards health behaviour. ${ }^{45}$ Individuals with a dominant avoidance tendency typically respond more strongly to threat cues, ${ }^{46}$ making them more receptive to loss-framing encouragement. ${ }^{47}$ However, no relevant variables were assessed in this study; we only proposed a research hypothesis that requires further investigation.

Fewer studies have explored the potential mechanism of message frames, which is of great significance for designing and applying message intervention. These studies found that attitudes and intentions may act as mediating factors of framing effect on behaviour, consistent with the theory of planned behaviour. ${ }^{23} 3248$ A negative frame may allow patients without behaviour change awareness to develop attitudes and behavioural intentions, thereby promoting behaviour. The interaction between message frame and individual time perspective also suggests that individual factors must be considered. ${ }^{38}$ Matching frames with individual factors may have a greater framing effect and help to promote the occurrence or maintenance of healthy behaviours. This is consistent with the view raised by Latimer et al that the effectiveness of the message frame may be dependent on the individual's thinking and feeling about behaviour, rather than just the function or nature of the behaviour itself. ${ }^{49}{ }^{50}$ Failing the influence of individual differences on message-framing effects may suppress the true framing effect and underestimate the utility of gain-framed and loss-framed appeals. ${ }^{49}$

\section{Limitations}

This review offers critical insights into the impact of message-framed education on health behaviours of patients with chronic diseases; however, several limitations have to be considered. Although we retrieved a considerable amount of literature from the database, only 11 articles met the inclusion criteria used in the present study. In the analysis, heterogeneity of different patient samples and health messages, and the diversity of outcome measurements did not permit a quantitative analysis, limiting the reliability of conclusions. Furthermore, this review only included research reported in English, which may exclude some studies; language constraints are also associated with potential bias in this systematic reviews. Only five studies measured actual behaviour changes, and only six studies just measured changes in cognitive variables immediately after the intervention. Of course, we know that there is still some distance between the initiation of behavioural intention to the occurrence and the maintenance of actual behaviour. Hence, future research needs to determine the effects of message framing on actual behaviour through long-term observation or objective measurement. Few studies have explored the underlying mechanisms of the influence of message framing on behavioural or cognitive variables. Future studies also need to explore the different effects of message framing according to the advocated behaviour and consider participants' existing beliefs and perceptions about the behaviour. ${ }^{50}{ }^{51}$ However, in general, the included studies have a relatively high risk of bias and low methodological quality, limiting the reliability of the results. Therefore, with these limitations of the present review, interpretation of the results should be made with caution.

\section{Implications for nursing}

One of the primary goals of this research is to provide suggestions for nurses and other healthcare professionals, extend the message-framing effect to chronic disease education interventions and improve patients' health, well-being and quality of life. The present findings add to the growing evidence that the way health education messages are are presented may more than the meaning of the content of messages. Proper design and delivery of messages can improve the persuasiveness of education, effectiveness and efficiency, enabling patients with chronic diseases to adopt and maintain health promotion behaviours. Furthermore, by empowering patients to be active decision makers rather than passive nursing recipients, patients' role in managing health-related issues can be strengthened.

\section{CONCLUSION}

Message framing can be an effective tool for encouraging health promotion information to promote health behaviours and beliefs in patients with chronic diseases. Besides, integration of message framing, loss framing into health education might especially be a promising strategy for motivating patients with chronic diseases to improve health behaviours and related cognitive variables. However, no firm recommendation could be made from this study. The best framework for improving the actual health behaviour of patients with chronic diseases, as well as its potential moderators and mediators, needs to be studied further and strengthened to guide health education.

Acknowledgements The authors thank the reviewers for their assistance and support.

Contributors RG and FL performed the conception and design of the study, drafted the article or revised it critically for important intellectual content. RG, HG, $\mathrm{FL}, \mathrm{YL}$ and $\mathrm{LX}$ performed the acquisition of data, or analysis and interpretation of data. RG, MS and TY performed the quality assessment. All authors read and gave final approval of the version to be submitted. Corresponding author FL can be responsible for the overall content as the guarantor.

Funding This study was funded by the Interdisciplinary Research Funding Programme for Doctoral Postgraduates of Jilin University (NNo. 101832 020DJX090).

Competing interests None declared.

Patient consent for publication Not applicable.

Ethics approval This study does not involve human participants.

Provenance and peer review Not commissioned; externally peer reviewed.

Supplemental material This content has been supplied by the author(s). It has not been vetted by BMJ Publishing Group Limited (BMJ) and may not have been peer-reviewed. Any opinions or recommendations discussed are solely those of the author(s) and are not endorsed by BMJ. BMJ disclaims all liability and responsibility arising from any reliance placed on the content. Where the content includes any translated material, BMJ does not warrant the accuracy and reliability 
of the translations (including but not limited to local regulations, clinical guidelines, terminology, drug names and drug dosages), and is not responsible for any error and/or omissions arising from translation and adaptation or otherwise.

Open access This is an open access article distributed in accordance with the Creative Commons Attribution Non Commercial (CC BY-NC 4.0) license, which permits others to distribute, remix, adapt, build upon this work non-commercially, and license their derivative works on different terms, provided the original work is properly cited, appropriate credit is given, any changes made indicated, and the use is non-commercial. See: http://creativecommons.org/licenses/by-nc/4.0/.

ORCID iD

Feng Li http://orcid.org/0000-0001-7423-8730

\section{REFERENCES}

1 World Health Organization. Noncommunicable diseases: key fact, 2018. Available: https://www.who.int/news-room/fact-sheets/detail/ noncommunicable-diseases [Accessed 03 Sep 2020].

2 World Health Organization. Noncommunicable diseases: fact sheets on sustainable development goals: health targets, 2017. Available: www.euro.who.int/_data/assets/pdf_file/0007/350278/Fact-sheetSDG-NCD-FINAL-25-10-17

3 Li Y, Wang DD, Ley SH, et al. Time trends of dietary and lifestyle factors and their potential impact on diabetes burden in China. Diabetes Care 2017;40:1685-94.

4 Yiengprugsawan VS, Browning CJ. Non-Communicable diseases and cognitive impairment: pathways and shared behavioral risk factors among older Chinese. Front Public Health 2019;7:296.

5 International Diabetes Federation (IDF). IDF diabetes atlas (8th ed), 2017. Available: http://www.diabetesatlas.org/resources/2017-atlas. html

6 Roser M, Ritchie H. Burden of disease. Our world in data, 2016. Available: https://ourworldindata.org/burden-of-disease [Accessed 03 Sep 2020].

7 Dennis SM, Zwar N, Griffiths R, et al. Chronic disease management in primary care: from evidence to policy. Med $\mathrm{J}$ Aust 2008;188:S53-6.

8 Koutsopoulou S, Papathanassoglou EDE, Katapodi MC, et al. A critical review of the evidence for nurses as information providers to cancer patients. J Clin Nurs 2010;19:749-65.

9 American Diabetes Association. Introduction: Standards of Medical Care in Diabetes-2018. Diabetes Care 2018;41:S1-2.

10 Jones LW, Sinclair RC, Courneya KS. The Effects of Source Credibility and Message Framing on Exercise Intentions, Behaviors, and Attitudes: An Integration of the Elaboration Likelihood Model and Prospect Theory ${ }^{1}$. J Appl Soc Psychol 2003;33:179-96.

11 Collins S. Explanations in consultations: the combined effectiveness of doctors' and nurses' communication with patients. Med Educ 2005;39:785-96.

12 Coster S, Norman I. Cochrane reviews of educational and selfmanagement interventions to guide nursing practice: a review. Int $J$ Nurs Stud 2009;46:508-28.

13 American Association of Colleges of Nursing. Nursing shortage fact sheet, 2008. Available: http://www.aacn.nche.edu/Media/FactSheets/ NursingShortage.htm [Accessed 01 Mar 2009].

14 Rothman AJ, Salovey P. Shaping perceptions to motivate healthy behavior: the role of message framing. Psychol Bull 1997;121:3-19.

15 O'Keefe DJ, Jensen JD. The advantages of compliance or the disadvantages of Noncompliance? A meta-analytic review of the relative persuasive effectiveness of Gain-Framed and Loss-Framed messages. Ann Int Commun Assoc 2006;30:1-43.

16 O'Keefe DJ, Jensen JD. The relative persuasiveness of gainframed and loss-framed messages for encouraging disease prevention behaviors: a meta-analytic review. J Health Commun 2007;12:623-44.

17 Kim HK, Lee TK. Conditional effects of Gain-Loss-Framed narratives among current smokers at different stages of change. $J$ Health Commun 2017;22:990-8.

18 Arora R, Stoner C, Arora A. Using framing and credibility to incorporate exercise and fitness in individuals' lifestyle. J Consum Mark 2006;23:199-207.

19 de Bruijn G-J. To frame or not to frame? Effects of message framing and risk priming on mouth rinse use and intention in an adult population-based sample. J Behav Med 2019;42:300-14.

20 Myers RE. Promoting healthy behaviors: how do we get the message across? Int J Nurs Stud 2010;47:500-12.

21 Robbins R, Niederdeppe J. Testing the role of narrative and GainLoss framing in messages to promote sleep hygiene among high school students. J Health Commun 2019;24:84-93.
22 Bernstein MH, Wood MD, Erickson LR. The effectiveness of message framing and temporal context on college student alcohol use and problems: a selective e-mail intervention. Alcohol Alcohol 2016;51:106-16.

23 Grady JL, Entin EB, Entin EE, et al. Using message framing to achieve long-term behavioral changes in persons with diabetes. Appl Nurs Res 2011;24:22-8.

24 Lee BJ, Gu MO. Comparison of the effects between positive message and negative message in diabetes mellitus education. Korean Diabetes J 2009;33:344-52.

25 Moher D, Liberati A, Tetzlaff J, et al. Preferred reporting items for systematic reviews and meta-analyses: the PRISMA statement. Ann Intern Med 2009;151:264-9.

26 Higgins PT, Green S. Cochrane handbook for systematic reviews of interventions. Version 5.1.0 [updated March 2011]. The Cochrane collaboration. Available: http://www.cochrane-handbook.org

27 Centers for Disease Control and Prevention (CDC), National Center for Chronic Disease Prevention and Health Promotion. About chronic diseases, 2019. Available: https://www.cdc.gov/chronicdisease/ about/index.htm

28 Stawnychy MA, Teitelman AM, Riegel B. Caregiver autonomy support: a systematic review of interventions for adults with chronic illness and their caregivers with narrative synthesis. J Adv Nurs 2021;77:1667-82.

29 Higgins JPT, Altman DG, Gøtzsche PC, et al. The Cochrane collaboration's tool for assessing risk of bias in randomised trials. BMJ 2011;343:d5928.

30 Ryan R, Hill S, Prictor M. Study quality guide, 2013. Available: http:// cccrg.cochrane.org/author-resources

31 Cunningham AT, Crittendon DR, White N, et al. The effect of diabetes self-management education on $\mathrm{HbA1c}$ and quality of life in AfricanAmericans: a systematic review and meta-analysis. BMC Health Serv Res 2018;18:367.

32 Park J, Kim SH, Kim JG. Effects of message framing and health literacy on intention to perform diabetes self-care: a randomized controlled trial. Diabetes Res Clin Pract 2020;161:108043.

33 Paragas ED, Barcelo TI. Effects of message-framed informational videos on diabetes management knowledge and self-efficacy. Int J Nurs Pract 2019;25:e12737.

34 Keyworth C, Nelson PA, Bundy C, et al. Does message framing affect changes in behavioural intentions in people with psoriasis? A randomized exploratory study examining health risk communication. Psychol Health Med 2018;23:763-78.

35 Li K-K, Ng L, Cheng S-T, et al. Reverse Message-Framing effects on Accelerometer-Assessed physical activity among older outpatients with type 2 diabetes. J Sport Exerc Psychol 2017;39:222-7.

36 Hirschey R, Lipkus I, Jones L, et al. Message framing and physical activity promotion in colorectal cancer survivors. Oncol Nurs Forum 2016;43:697-705.

37 Bassett-Gunter RL, Martin Ginis KA, Latimer-Cheung AE. Do you want the good news or the bad news? gain- versus loss-framed messages following health risk information: the effects on leisure time physical activity beliefs and cognitions. Health Psychol 2013:32:1188-98.

38 Zhao X, Villagran MM, Kreps GL, et al. Gain versus loss framing in adherence-promoting communication targeting patients with chronic diseases: the Moderating effect of individual time perspective. Health Commun 2012;27:75-85.

39 Trupp RJ, Corwin EJ, Ahijevych KL, et al. The impact of educational message framing on adherence to continuous positive airway pressure therapy. Behav Sleep Med 2011;9:38-52.

40 Janke EA, Spring B, Weaver F. The effect of message framing on self-management of chronic pain: a new perspective on intervention? Psychol Health 2011;26:931-47.

41 McCall LA, Ginis KAM, Martin Ginis KA. The effects of message framing on exercise adherence and health beliefs among patients in a cardiac rehabilitation program. J Appl Biobehav Res 2004;9:122-35.

42 Kim S, Song Y, Park J, et al. Patients' experiences of diabetes selfmanagement education according to Health-Literacy levels. Clin Nurs Res 2020;29:285-92.

43 Coskun S, Bagcivan G. Associated factors with treatment adherence of patients diagnosed with chronic disease: relationship with health literacy. Appl Nurs Res 2021;57:151368.

44 Prochaska JO, Redding CA, Evers KE. The transtheoretical model and stages of change. In: Health behavior and health education: theory, research and practice. 4th ed. San Francisco, CA, US: Jossey-Bass, 2008: 97-121.

45 Leeuw M, Goossens MEJB, Linton SJ, et al. The fear-avoidance model of musculoskeletal pain: current state of scientific evidence. $J$ Behav Med 2007;30:77-94. 
46 Carver CS, Sutton SK, Scheier MF. Action, emotion, and personality: emerging conceptual integration. Personality and Social Psychology Bulletin 2000;26:741-51.

47 Mann T, Sherman D, Updegraff J. Dispositional motivations and message framing: a test of the Congruency hypothesis in college students. Health Psychol 2004;23:330-4.

48 Ajzen I. The theory of planned behavior. Organ Behav Hum Decis Process 1991;50:179-211.

49 Latimer AE, Brawley LR, Bassett RL. A systematic review of three approaches for constructing physical activity messages: what messages work and what improvements are needed? Int J Behav Nutr Phys Act 2010;7:36.

50 Werrij MQ, Ruiter RAC, Van 't Riet J, et al. Self-efficacy as a potential moderator of the effects of framed health messages. $J$ Health Psychol 2011;16:199-207.

51 Lee AY, Aaker JL. Bringing the frame into focus: the influence of regulatory fit on processing fluency and persuasion. $J$ Pers Soc Psychol 2004;86:205-18. 